\title{
Design Factors and Use of Ear Protection*
}

\author{
C. G. RICE and R. R. A. COLES $\uparrow$ \\ From the Audiology Group, Institute of Sound and Vibration Research, \\ University of Southampton
}

The problems of protecting the ear against hazardous noise are the subject of a general review, supported where relevant by data from the authors' own researches. Ear protectors are classified into two main typesplugs and muffs-and the general principles of their function and limitations are stated. Examples of representative ear protectors are given in more detail, with particular respect to their relative merits and pure-tone attenuation characteristics. The effects of earplugs on speech communication are considered, and the relationships between pure-tone attenuation and protection against continuous noise are discussed in some detail. The results of temporary threshold shift (T.T.S.) reduction studies of the efficiency of V.5IR and Selectone-K earplugs in protecting against reverberant and non-reverberant impulsive noises are presented. The design requirements of ear protectors and some of the problems created by them are also outlined.

When noise reduction and isolation measures have failed to reduce a noise to levels acceptable by octave-band analysis used in conjunction with damage risk criteria, the provision of ear protection has to be considered. The object of such protection is to reduce the amount of sound energy transmitted to the inner ear so that protection may be afforded to the cochlea.

\section{Basic Types of Ear Protectors}

\section{Reduction of Transmission by Air Conduc- tion}

Earmuffs These are rigid cups specially designed to cover completely the external ears. Two such cups are held in place by an adjustable headband or are mounted in a helmet. Each cup has a soft foamfilled or fluid-filled cushion to ensure a good fit between the cup and the head.

Earplugs These are provided in one of the following forms which are suitable for insertion into the ear canal:

Prefabricated earplugs, made of rubber or plastic, and usually supplied in a variety of sizes.

^This article is based on a paper read to the Production Engineers Research Association at its Noise Control Conference at Melton Mowbray on 19-20 October, 1965.

†Surgeon Commander R. R. A. Coles is also Head of the Audiology Department of the Royal Naval Medical School, Alverstoke, Hants.

Received for publication July 2, 1965 .
Temporary earplugs in the form of a low-cost, disposable material, such as wax-impregnated cotton wool or specially fine glass wool described as 'glass-down'.

Reduction of Transmission by Bone Conduction Anything which impedes normal sound conduction causes a conductive hearing loss, although the magnitude of such is limited to about $50 \mathrm{~dB}$, because after reduction of intensity by this amount the remaining sound is conducted through the bones of the skull directly to the inner ear, so avoiding the ossicular chain. This bone conduction is important in several contexts. It accounts for the 'mirror-image' audiogram found in patients with severe unilateral deafness, and in clinical diagnosis it means that a hearing loss much greater than $50 \mathrm{~dB}$ cannot be wholly conductive. Moreover, in ear protection, the maximum amount by which an ear protector can reduce the sound reaching the ear is limited to about $35 \mathrm{~dB}$ at $250 \mathrm{c} / \mathrm{s}$ up to about $60 \mathrm{~dB}$ at the higher frequencies: the addition of helmets which seal off the whole head can, however, increase the sound attenuation by another Io $\mathrm{dB}$, when conduction of sound by the body as a whole adds a further limitation.

Helmets Helmets are commonly used to support earmuffs or earphones and cover the bony portion of the head in an attempt to reduce bone-conducted sound. They are particularly suited for use in high noise levels, both for communication and for reasons 
of additional safety such as eye, 'bump' or ballistic protection. With good design and careful fitting of the sealing between the edges of the helmet and the skin of the face and neck, a further 5 to $10 \mathrm{~dB}$ of sound attenuation can be obtained in addition to that already provided by the earmuffs or earphones within the helmet.

\section{Requirements of Ear Protectors}

Noise Reduction The protector should be chosen to reduce the noise to an acceptable level. Earplugs are less effective than earmuffs, though either can be inefficient if incorrectly fitted. In general, earplugs can be used in noise levels below I Io $\mathrm{dB}$, whereas earmuffs are efficient in noise levels up to about $125 \mathrm{~dB}$. Both can be used for even higher levels of short duration, the degree of ear protection required depending on the duration of exposure.

Comfort The acceptability of an ear protector depends on its comfort. All protectors are uncomfortable if worn for long periods and, in general, earplugs are less comfortable than earmuffs despite the fact that earmuffs are heavier and more bulky and are liable to cause perspiration.

Speech Communication The use of an ear protector does not necessarily reduce the ability to communicate. The hearing state of the user, the type of noise, and the type of plug all contribute (Coles and Rice, 1966b). It is important to judge each situation on its merits and to select a protector accordingly. Earmuffs can incorporate electronic communication aids, and earplugs can be designed to have frequency or amplitude-selective properties which help communication in certain circumstances.

Other Requirements It should be possible to fit and remove the protectors quickly and easily. They should be long-lasting, robust, and not liable to deterioration, they should be resistant to perspiration and non-toxic. The cost of an ear protector should be judged in relation to its expected life and the protection required: the prices range from a few pence to several pounds. The non-disposable type of protector should also be capable of being easily cleaned, repaired or replaced, as necessary.

\section{Factors influencing Noise Reduction Properties}

Earmufis The noise can be transmitted by the following paths: (a) by air leaks between the cushion and the head;

(b) by transmission through the cushion or earcup;

(c) by vibration of the earmuff acting as a rigid body; and

(d) by transmission through the skull ( 35 to $50 \mathrm{~dB}$ limitation of attenuation due to bone conduction).

Effects $(a)$ to $(c)$ can be controlled by the design of the cushions and of the cups. The opening to take the pinna should be as small as possible, whereas the enclosed volume should be large. Air leaks will impair the efficiency of attenuation of the low frequencies and may be reduced by having an adequate tension in the headband, especially by the use of the fluid-seal type of cushion.

Earplugs The noise can be transmitted by the following paths:

(a) by air leaks between the plug and the ear canal;

(b) by propagation through the plug itself;

(c) by causing the plug to vibrate like a piston; and

(d) by transmission through the skull.

The design of earplugs is really a compromise as they are made of soft, resilient plastic or rubber for comfort, but in consequence they more easily deform under the action of sound waves and so allow the transmission of sound through them. Small air leaks due to a poor fit will reduce the attenuation properties below $\mathrm{I}, 000 \mathrm{c} / \mathrm{s}$, a fact put to deliberate use in some types of frequency-selective earplugs, e.g., the Selectone-K.

\section{Evaluation of Acoustic Properties}

The most important consideration in an ear protector is its attenuation and, consequently, the sound energy it keeps out of the ear of the average person.

The American Standard (1957) method of measuring the attenuation is widely accepted and involves a free-field binaural threshold shift technique. In this, the threshold of hearing for selected pure tones is measured in a free field using both ears of each of a group of subjects with normal hearing. The thresholds are also measured with each subject wearing the selected ear protectors, and the average difference between these two thresholds is the attenuation.

Other subjective methods of measuring attenuation include loudness-balance techniques and the monaural free-field or earphone threshold shift for pure tones: selected noise bands can be used in place of pure tones. Similar measurements have been made in various laboratories using artificialhead or artificial-ear techniques, but their results differ somewhat and need careful interpretation in 
view of the fact that the subjective methods are in most respects more realistic.

We need to know how variable the amount of protection may be from individual to individual, even when the plugs are fitted carefully. Ear protectors can be judged with respect to this quality by a comparison of the standard deviation (in $\mathrm{dB}$ ) of the attenuation determinations at each frequency. The standard deviations include other components, principally that due to variations in audiometric performance by each subject between test and retest. In comparing one ear protector with another, the major differences in standard deviation are attributed to the inherent difficulty in completely occluding all shapes and sizes of ear. In the case of prefabricated earplugs this is particularly difficult when there are only a few sizes available.

\section{Commercially Available Ear Protectors}

Earmufis The best kind of earmuff is that which embodies the circumaural fluid-seal principle, developed by Shaw and Thiessen (1958). The muff itself is a hard, bulky shell which covers the whole ear, but where it fits the head around the pinna there is a PVC ring containing a fluid-usually glycerine. This conforms to the contours of the head and so reduces sound leakage. An example of such a muff is shown (Fig. I). Only one size is normally provided, but the length of the headband is adjustable. Such earmuffs are the most efficient ear protectors that can be made; adding earplugs beneath properly fitting muffs of this type gives very little increase in sound attenuation (except perhaps at frequencies below $500 \mathrm{c} / \mathrm{s}$, which are usually of less importance for damage risk or speech interference), because transmission by bone conduction then takes over. However, they can be uncomfortable, bulky, and, necessarily, tight-fitting; the ears also tend to become rather hot and to perspire beneath them. Despite these disadvantages they must be considered essential whenever the noise level is very high and the best possible means of ear protection is

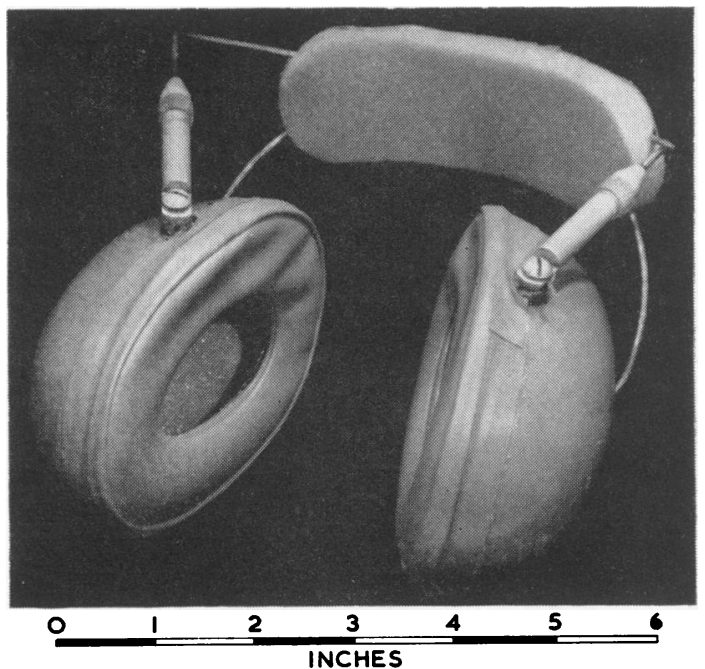

Fig. I. A modern type of earmuff (Eargards, by DenisFerranti Meters Ltd., Bangor).

indicated. The pure-tone attenuation characteristics are shown in Table II and Figure 4.

Earplugs Some commonly used earplugs are described below:

$V .5 I R$ One of the most efficient earplugs, and certainly the most widely used of the types that are intended for personal issue and repeated use, is the V.5IR plug developed by Mine Safety Appliances Inc. in the United States of America during World War II. It is illustrated in Figure 2. It consists of a soft plastic bung carrying a flexible flange in order to conform to the shape of the external meatus and make as complete a seal as possible. The plug was originally produced in five sizes, but several manufacturers (mistakenly in the authors' opinion) have reduced them to three: however, recent demands

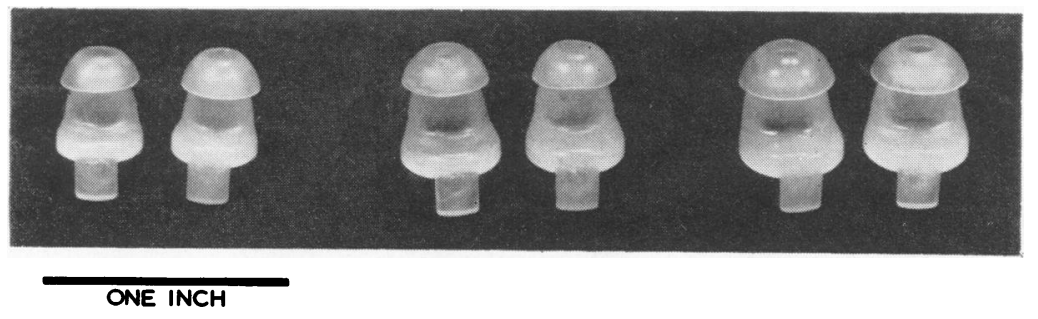

FIG. 2. The V.5IR type of earplug (Sonex, by Amplivox Ltd., Wembley). 
from users have in some cases resulted in a reversion to five sizes.

The repeated-use type of earplug has a number of disadvantages which limit its practical acceptability. In order to be effective it has to fit tightly and, inevitably, this is uncomfortable; quite often, because of this and the irregular shape of the ear canals of many persons, an incorrect size of plug is selected or the plug is not inserted far enough, or a good fit cannot be obtained. Further the plugs need to be kept clean to minimize the risk of otitis externa; they may easily be lost; and they tend to harden in time with repeated washing. The puretone attenuation characteristics are shown in Table II and Figure 4.

'Glass-down' Probably the most practical-and acceptable to the user-of the disposable forms of earplugs are those made of 'glass-down'. This is a form of glass wool in which the fibres are so fine that they form a material of down-like softness which, as far as we have been able to ascertain from its now extensive use both in this country and abroad, is quite harmless even to the delicate skin of the ear canal. To be used effectively and, to avoid pieces of 'glass-down' being left in the meatus, the plug must be folded according to the instructions provided with it; the method of forming a plug is illustrated (Fig. 3). For industrial use on a large scale, a satisfactory form of dispenser is available. The puretone attenuation characteristics are shown in Table II and Figure 4.

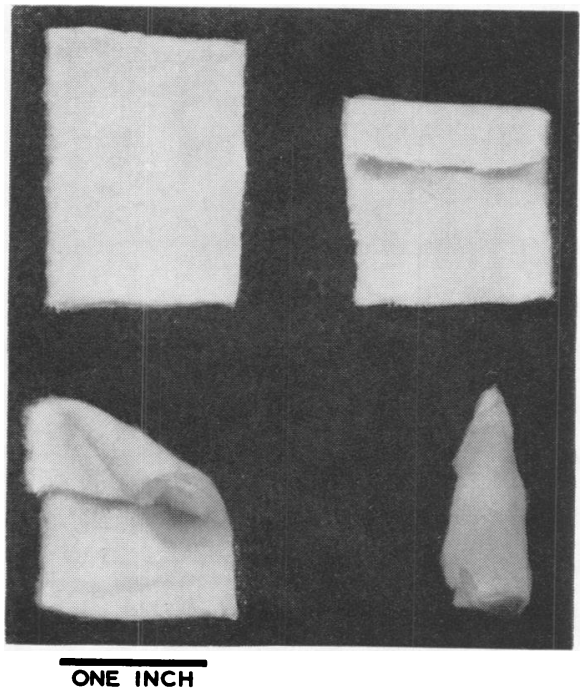

Fig. 3. Method of forming a 'glass-down' earplug (AntiNoise, by Ardente Industrial Services Ltd., Windsor).
Cotton-wool Cotton-wool earplugs are not advised on account of their inefficiency and the false sense of security which their use engenders; further, although the types of cotton wool supplied more recently for medical purposes appear to have rather finer fibres than hitherto, we have still found them to be rather unsatisfactory. The pure-tone attenuation characteristics are shown in Table I.

\section{TABLE I}

Pure-tone Attenuation Provided by Two Forms of CotToN WoOL

Type of Cotton Attenuation (dB) at Following

Wool Frequencies $(c / s)$ :

$250500 \quad 1,0002,000 \quad 4,000 \quad 8,000$

Old type:

coarse fibres

$\begin{array}{llllll}3 & 3 & 4 & 7 & \text { 10 } & \text { 19 }\end{array}$

$\begin{array}{lllllll}\text { finer fibres } & 5 & 9 & \text { 10 } & 15 & 16 & 25\end{array}$

If the cotton wool is mixed with petroleum jelly or paraffin wax it becomes very much more efficient. The former is rather messy and not very practicable; the latter has to be preformed into earplugs and is available in a number of commercial forms. These preformed plugs have a further disadvantage in their lack of elasticity: after a while, the repeated alterations in the shape of the ear canal caused by jaw movements compress the relatively inelastic plug into a shape that no longer fits tightly, and the plug then becomes inefficient.

Taking all factors into consideration, the authors believe 'glass-down' to be the earplug of choice in most industrial noise situations provided every effort is made to ensure that it is properly formed and inserted.

\section{Pure-tone Attenuation Characteristics}

The pure-tone attenuation characteristics of the ear protectors already mentioned are shown in Table II and Figure 4. The characteristics of ear protectors have been measured in many laboratories and results differ considerably; it is not advisable therefore to compare attenuation of ear protectors where the results have been obtained in different laboratories, unless there are large numbers of evaluations on a given type of ear protector when the various results may be averaged. The data given below have all been obtained in the Commonwealth Acoustic Laboratories (Piesse, 1962).

It is interesting to note the small standard deviations and the high level of attenuation achieved with fluid-seal ear muffs. The standard deviations of the results from 'glass-down' are also distinctly less than those of V.5IR plugs or waxed cotton wool, 
TABLE II

\begin{tabular}{|c|c|c|c|c|c|c|c|}
\hline & TENUATION AND STAI & N $\mathrm{CH}$ & TERIS & OF EAI & ?ROTEC & & \\
\hline Ear Defender & Measurement & Freq & $y(c / s$ & & & & \\
\hline & . & 250 & 500 & 1,000 & 2,000 & 3,000 & 4,000 \\
\hline Fluid-seal muffs* & Attenuation (dB) & 28 & 38 & 39 & $4 I$ & 44 & 47 \\
\hline & Standard deviation & 3 & 4 & 4 & 7 & 4 & $\begin{array}{r}71 \\
4\end{array}$ \\
\hline V.5IR plug $\dagger$ & Attenuation (dB) & II & 13 & 19 & 27 & 30 & 25 \\
\hline & Standard deviation & 7 & 9 & 10 & 9 & 6 & 5 \\
\hline ‘Glass-down’ $\ddagger$ & Attenuation (dB) & II & 13 & 17 & 29 & 34 & 35 \\
\hline & Standard deviation & 5 & 4 & 7 & 6 & 7 & 7 \\
\hline Waxed cotton wool & Attenuation (dB) & 10 & 12 & 16 & 27 & 31 & 32 \\
\hline & Standard deviation & 9 & 9 & 8 & II & I0 & 9 \\
\hline Dry cotton wool & Attenuation (dB) & 3 & 4 & 8 & 12 & 14 & 12 \\
\hline & Standard deviation & 2 & 3 & 3 & 6 & 4 & 4 \\
\hline
\end{tabular}

*Eargards, by Denis-Ferranti Meters Ltd., Bangor (Fig. I).

$\dagger$ The original Mine Safety Appliances plug (similar to those illustrated in Fig. 2).

\$The Swedish product known as Billesholms; marketed in U.K. as Anti-Noise (Fig. 3).

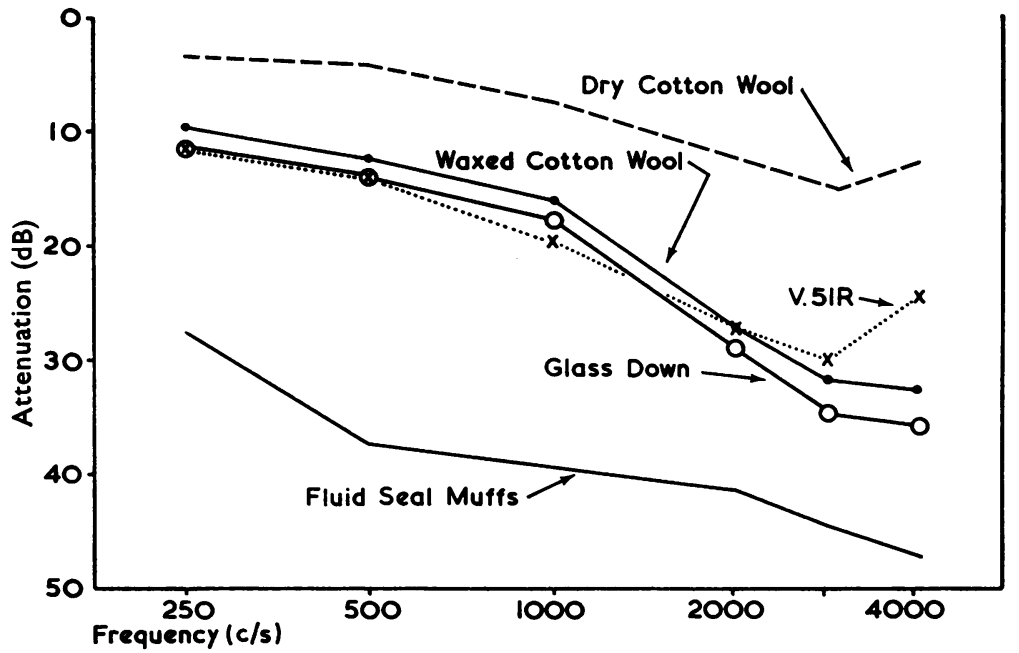

Fig. 4. Pure tone attenuation characteristics of some ear protectors (data from Piesse, 1962).

although all three show similar mean attenuation values.

\section{Ear Protectors with Special Characteristics}

Frequency-selective Earplugs (e.g., SelectoneK) The use of acoustic, low-pass filters in the design of earplugs, and the Selectone-K earplug which incorporates these ideas, has been described by Zwislocki (1951, 1952). The plug is illustrated in Figure 5. The pure-tone attenuation characteristics of this plug (Coles and Rice, 1966a), using a monaural earphone threshold-shift technique, are shown in Table III in comparison with those of the V.5IR plug, the latter figures being in close agreement with those obtained by Piesse (see Table II).
From Table III it can be seen that the attenuation below 2,000 c/s is very small for the Selectone$\mathrm{K}$. This enables the lower speech frequencies to be passed more easily than is the case with the V.5IR. The design of the plug is such, however, that the tiny holes provide a strong frictional component to impulsive types of noise: in this respect therefore the plug can be said to have amplitude-sensitive characteristics also. These characteristics make the Selectone-K most suitable for use when communication is required during periods of relative quiet between bursts of impulsive noise.

When worn in the presence of a continuous noise, on the other hand, speech communication is impaired rather more than would be the case with the V.5IR. This is due to the fact that low-frequency masking noise is passed in addition to the speech. 

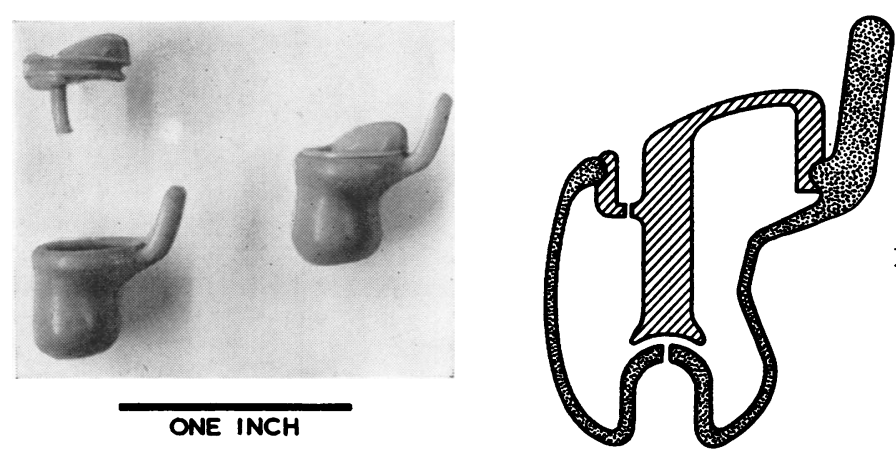

Fig. 5. The Selectone-K earplug (available in three sizes from Ardente Industrial Services Ltd., Windsor).

TABLE III

Pure-tone Attenuation Characteristics of Selectone-K and V.5IR Earplugs

\begin{tabular}{|c|c|c|c|c|c|c|c|}
\hline \multirow[t]{2}{*}{ Earplug } & \multicolumn{6}{|c|}{ Attenuation $(d B)$ for Following Frequencies $(c / s)$ : } & \multirow{2}{*}{$\begin{array}{l}\text { Attenuation for } \\
\text { Speech (P.B. words } \\
50 \% \text { score) }\end{array}$} \\
\hline & 500 & 1,000 & 2,000 & 3,000 & 4,000 & 6,000 & \\
\hline $\begin{array}{l}\text { Selectone-K } \\
\text { V.5IR }\end{array}$ & $\begin{array}{r}6 \\
13\end{array}$ & $\begin{array}{l}\text { I0 } \\
17\end{array}$ & $\begin{array}{l}21 \\
26\end{array}$ & $\begin{array}{l}3 I \\
28\end{array}$ & $\begin{array}{l}31 \\
27\end{array}$ & $\begin{array}{l}34 \\
25\end{array}$ & $\begin{array}{l}15 \\
19.5\end{array}$ \\
\hline
\end{tabular}

Amplitude-selective Earplugs (e.g., LeeSonic Ear Valv) This plug has been designed to operate only in the presence of high intensity noise. This implies that little interference with speech would be expected under relatively quiet conditions, which is in fact the case. The Ear Valv, as its name implies, is designed to be self-regulating, in as much that in the presence of loud impulsive noise a valve situated within the plug is momentarily thrust into a closed position by means of the energy present in the noise. In high levels of continuous noise the valve is said to operate under a 'continuous reciprocating actuation'.

The pure-tone attenuation characteristics have been measured by Piesse (I962), and from these one would expect the Ear Valv to have advantages over the Selectone-K with respect to speech communication. The efficiency of the Ear Valv in protection against noise has not, as far as the authors have been able to ascertain, been thoroughly examined. Reports in the literature suggest that amplitudeselective earplugs, depending on the action of such a valve, might require extremely high sound pressure levels to operate (Thiessen, 1962), for example, in rifle firing, when the levels can be above $160 \mathrm{~dB}$. Piesse (I962) and Dickson, Hinchcliffe and Wheeler (1954) suggest that the plug might not be very efficient in continuous noise. However, it is noteworthy that loudness-balance techniques, by which attenuation is measured well above threshold, have indicated rather better attenuation properties (Neely, 1965). Also, subjective impressions of the
Ear Valv and their evident popularity in rifle clubs suggest that they may be effective against intermittent impulsive types of noise: it is possible though that this may be due to a frictional resistance component similar to that of the Selectone-K rather than to operation of the valve.

It appears that most kinds of earplug have some degree of amplitude-selectivity, though this property is most marked where there is a narrow aperture (or apertures) in the long axis of the plug. The purpose of the aperture is to reduce the attenuation of sounds of low frequency and thereby allow minimal interference with the hearing of speech. The property of amplitude-selectivity has been indicated by Neely (1965) in his comparison of the threshold and loudness-balance attenuation measurements of two earplugs, and also by artificial-ear measurements of attenuation provided by Nosonic (MallockArmstrong) earplugs and earmuffs in impulsive noise fields (Golden and Clare, 1965). A gradual increase in the attenuation properties of 'glassdown' with a rise in the sound pressure level has also been observed during recent experiments (Coles and Mrs. V. M. Priede, 1965, unpublished data) in which subjects with one ear plugged made loudnessbalance judgements at $20,40,60$, and $80 \mathrm{~dB}$ sensation level in the plugged ear.

\section{Effects of Ear Protectors on Speech Communication}

It is sometimes desirable to evaluate ear protec- 
tors in terms of their effect on speech communication. The mean attenuation in the 500 to $2,000 \mathrm{c} / \mathrm{s}$ range is usually taken as a rough guide, but recently, from a series of speech and pure-tone thresholdshift measurements using a monaural earphone listening technique, the authors (in association with Miss Helen Ferres of the R.A.F. Institute of Aviation Medicine, Farnborough) have derived a formula for calculation of the shift in the speech reception threshold (level for $50 \%$ intelligibility of P.B. words) caused by earplugs. It was found that:

$$
\text { speech attenuation }(\mathrm{dB})=6+\frac{x_{1}}{3}+x_{2}-\frac{x_{2}^{2}}{40}
$$

where $x_{1}$ and $x_{2}$ are the pure-tone attenuations at $500 \mathrm{c} / \mathrm{s}$ and $1,000 \mathrm{c} / \mathrm{s}$ respectively. The value at $2,000 \mathrm{c} / \mathrm{s}$ contributed nothing to the precision of the formula.

The limitations of this formula are apparent due to the negative sign for the $x_{2}^{2}$ term. For values of $x_{2}$ greater than 20 the modulus of $\left(x_{2}-\frac{x_{2}^{2}}{40}\right)$ decreases. Hence, the speech attenuation would be expected to decrease, which is not the case. It was found that the formula holds best for values of $x_{1}$ and $x_{2}$ in the region of 6 to $17 \mathrm{~dB}$. For example, using the data in Table III, the calculated speech attenuations were I5.5 dB and $20 \mathrm{~dB}$ for the Selectone-K and V.5IR plugs respectively. With values of $x_{1}$ and $x_{2}$ lower than about $5 \mathrm{~dB}$, the constant value of $6 \mathrm{~dB}$ in the formula appears to be slightly high. For example, using an earplug specially designed to cause minimum interference with speech communication, the formula was applied to pure-tone and speech measurements in both a monaural earphone and a monaural free-field listening condition. These results are shown in Table IV and indicate that the previously derived formula is not an artefact of earphone listening. It may therefore be used in the calculation of the likely effects of earplugs on the hearing of speech, the shift in the speech reception threshold (S.R.T.) having been shown to be the most applicable measure of such effects (Coles and Rice, 1965) in real-life situations.

\section{TABLE IV}

SPEech ReCeption Threshold (S.R.T.) Shift MEasurement and Calculated Speech Attenuation for 12 Subjects Using a Specially Designed Earplug Under Earphone AND FREE-FIELd Listening CoNDITIONS

\begin{tabular}{lrr} 
& $\begin{array}{l}\text { Earphone } \\
\text { Listening } \\
(d B)\end{array}$ & $\begin{array}{l}\text { Free-field } \\
\text { Listening } \\
(d B)\end{array}$ \\
\hline Pure-tone attenuation at $500 \mathrm{c} / \mathrm{s}$ & 0.5 & 0.5 \\
Pure-tone attenuation at $\mathrm{I}, 000 \mathrm{c} / \mathrm{s}$ & -1.7 & -1.4 \\
Calculated speech attenuation & 4.4 & 4.7 \\
Measured S.R.T. shift & 2.5 & 2.8
\end{tabular}

The constant value in the formula, which seems to lie between 3 and $6 \mathrm{~dB}$, is an interesting by-product worthy of discussion. When an ear canal is partially obstructed by wax and this is removed, it is commonly remarked by the patient that other people's voices seem to have become louder. Although this fact is undemonstrable by pure-tone threshold audiometry, it is tempting to state that it does represent a true improvement, although we do not yet have direct experimental evidence for this. The formula predicts that once anything is inserted into the ear canal, whatever its measurable attenuation characteristics are, there is immediately a shift of some 3 to $6 \mathrm{~dB}$ in the speech attenuation. The literature contains similar evidence, some of which has already been mentioned in connexion with amplitude-selectivity and which will be discussed further in the next section concerning the actual protective properties of ear protectors.

With regard to earmuffs, we have found no direct data on their effects on speech reception. The authors' formula is based on earplug studies and, as already noted, must be limited to attenuation values at $\mathrm{r}, 000 \mathrm{c} / \mathrm{s}$ that are well below those provided by earmuffs. There are, however, indications from the threshold and loudness-balance studies of Hershkowitz and Levine (1957) that the elevation of the speech threshold by earmuffs may be rather less than expected from the pure-tone threshold attenuation measurements.

There are a number of other factors to be considered concerning the auditory effects of wearing ear protectors. Provided that speech sounds are of sufficient intensity, they will be heard without degradation by a normal-hearing person wearing them. On the other hand, in persons with a preexisting, high-tone, perceptive hearing loss, their already reduced ability of speech discrimination at optimum levels of amplification is likely to be reduced somewhat further when ear protectors are worn (Coles and Rice, 1966b).

The above remarks refer to quiet conditions. In a noisy background the position is quite different. At noise levels of about $85 \mathrm{~dB}$, if the voice can be raised sufficiently loudly to be heard at all, then ear protectors make no difference (in normal-hearing persons). This is because the perceived level of both the voice (signal) and the noise is lowered equally by the ear protectors, i.e., the signal-to-noise ratio is unaltered. Further, there is evidence that at levels above about $85 \mathrm{~dB}$ the use of ear protectors may actually be beneficial towards direct vocal communication (Kryter, 1946). In even more intense noise (I IO to $130 \mathrm{~dB}$ ), marked improvements in intelligibility of speech in a communications system have 
been found when earplugs were worn under the earphones (Pollack, 1957).

The position of persons with impaired hearing when using ear protectors in a noisy environment does not appear to have been studied, but theoretical considerations lead us to conclude that the use of ear protectors may have disadvantages for these people, especially when they are listening for 'indicator sounds', e.g., some warning bells, aberrant machinery sounds, etc. To some extent, also, even normal-hearing persons may hear such 'indicator sounds' less clearly when wearing ear protectors.

One of the greatest of recent advances in communication headsets has been the embodiment of telephone receivers inside fluid-seal noise-excluding earmuffs. This has a double benefit in practice: the listener is dependent on wearing the muffs for markedly improved communication and, while so listening, he is at the same time protected against the noise. The headsets may be connected by a flex to a plug-in communication system, or, in some cases, magnetic induction-loop receivers may be incorporated and the wearer can then hear instructions anywhere within the area of the magnetic loop without the need of a trailing flex.

\section{Actual Protective Qualities of Ear Protectors}

It has been stated that the threshold shift technique using earmuffs may result in figures which are $6 \mathrm{~dB}$ too optimistic (Hershkowitz and Levine, 1957). Also, the data of Sivian and White (1933) and Munson and Wiener (1952) suggest that the difference between the earphone and free-field measurements of auditory threshold (a phenomenon known as the 'missing $6 \mathrm{~dB}$ ' and more recently referred to in detail by Rudmose (1962)) may influence the attenuation provided by earplugs compared with earmuffs. If this difference was even partly due to masking of thresholds by physiological noise when earphones were worn, then inserting earplugs might be expected to have a similar effect.

On arguments such as these, presumably, some earplug manufacturers in their advertisement material have added $6 \mathrm{~dB}$ to the measured threshold shift attenuation figures. Michael (1965) concludes that this practice is unjustified, but it is noteworthy that Neely (1965) found with two different earplugs an average of $8 \mathrm{~dB}$ and $3.5 \mathrm{~dB}$ more attenuation at $500 \mathrm{c} / \mathrm{s}$ and $\mathrm{I}, 000 \mathrm{c} / \mathrm{s}$ respectively when using an earphone loudness-balance technique. The authors' formula also predicts an added $6 \mathrm{~dB}$ for this frequency range. Both Neely's loudness-balance measurements and our S.R.T. shift measurements were supra-threshold techniques, which must be more applicable than threshold techniques as an indicator of an ear protector's performance in intense noise. Masking by physiological noise could not have affected the attenuation results from suprathreshold techniques; therefore, these results tend to support the theoretical application of the 'missing $6 \mathrm{~dB}$ ' (i.e., adding it to the threshold attenuation figures) when considering supra-threshold attenuation of earplugs at frequencies at and below $I, 000 \mathrm{c} / \mathrm{s}$.

These uncertainties, together with the occurrence of amplitude-selectivity, should be borne in mind when using pure-tone attenuation data as a measure of the amount by which intense steady-state (e.g., machinery) types of noise would be reduced by ear protectors in order to comply with damage risk criteria.

To establish the effectiveness of an ear protector under conditions of high intensity, impulsive noise (e.g., impacts, gunfire) a much more complicated procedure is needed. Generally, it can be stated that the pure-tone attenuation figures give a low estimate of the effectiveness, since anything placed in the meatus will provide a frictional component for the absorption of high-intensity, acoustic transients, whereas this mechanism is less effective for most continuous sounds. The method used to evaluate the effectiveness of ear protectors under impulsive noise conditions is known as the temporary threshold shift reduction (T.T.S.R.) and has been developed at the United States Army Medical Research Laboratory, Fort Knox, by Fletcher and Loeb (1962). Its application is illustrated in Fig. 6, in which the results of the authors' evaluation of V.5IR and Selectone-K earplugs are illustrated. In the open, both plugs gave virtually complete protection against the T.T.S. which resulted from rifle shots when no plugs were worn; in an enclosed hut, the noise exposure was naturally more severe and the Selectone-K was found to be slightly less effective.

\section{Practical Problems with Ear Protectors}

Resistance of personnel towards using ear protectors is universal though varying in degree. Objections are in many cases very reasonable but have to be weighed against the hazard to hearing. In other cases, the objections are less well founded and depend on such factors as self-consciousness, carelessness, bravado, tradition, and unawareness of the dangers : in these cases, the resistance may largely be overcome by discipline, education, and example.

The more valid objections include the following:

Discomfort Earplugs have to be rather uncomfortably tight in order to be effective, though this seems to be less true of 'glass-down' than of other types. With a little persistence, personnel 


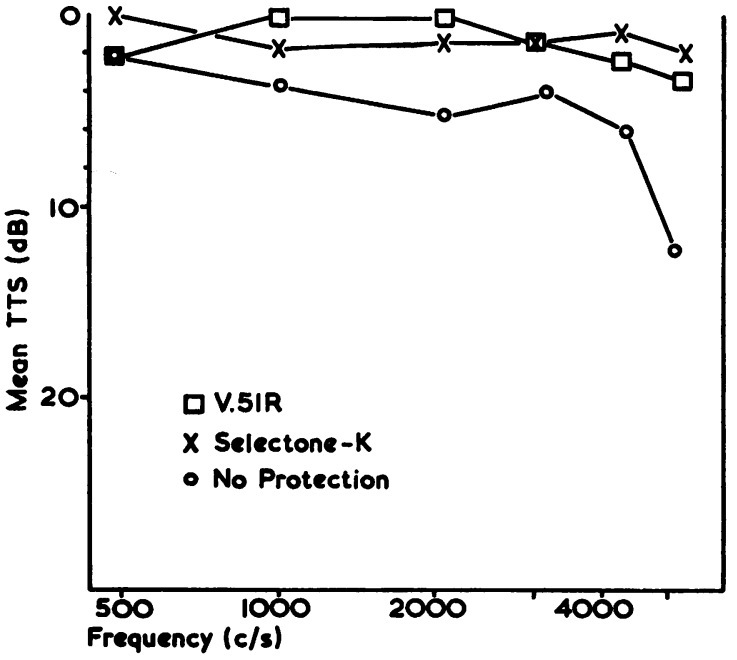

(a)

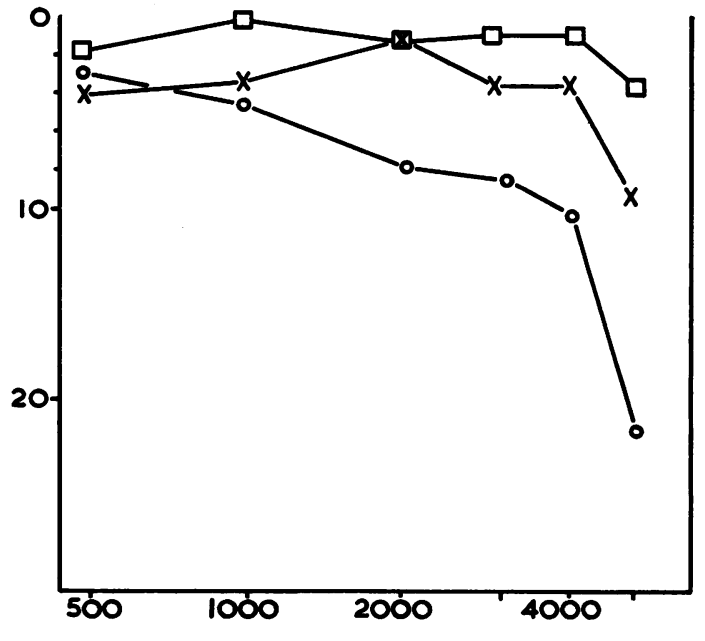

(b)

FIG. 6. Mean T.T.S. of five noise-sensitive subjects under (a) open range conditions and (b) reverberant hut conditions.

become used to the discomfort. Earmuffs tend to make the ears feel very hot and sweaty, and their bulk and tightness are apt to cause headaches. Again, persistence is the answer, but, for reasons of hygiene and efficiency, each man should have his own personal pair of muffs.

Ear Infections In ear infections earplugs are contra-indicated; indeed, external otitis can be caused by earplugs, particularly when repeated-use types are not properly cleaned after use. Earmuffs provide a reasonable alternative in these special cases. Occasionally, sensitization of the skin of the ear canal or around the ear also occurs; in this connexion, no particular type of material appears to be specially at fault.

Difficulty with Communication This aspect has already been discussed in some detail and, in most instances of workers in continuous noise, explanation and demonstration will reduce wearer resistance. In intermittent noise situations the problem is more difficult, and careful consideration has to be given to the opposing factors of noise hazard without plugs and possible inefficiency or danger with plugs.

Difficulty in Listening to Machinery Sounds or Hearing Warning Signals In general, the signal-to-noise ratio considerations that govern the hearing of speech against a noisy background are also relevant to the hearing of other types of signal. However, it is not correct to be emphatic on this point since on rare occasions earplugs can interfere with perception of these sounds, especially in persons with a pre-existing, high-tone hearing loss (as is likely to be found in many men working in intense noise environments). Moreover, most engineers have learned to listen for aberrant sounds, which may indicate a hot bearing, etc., without wearing ear protectors. When, later on in their working life, they are given ear protectors, they very naturally feel a loss of confidence in their ability to detect and interpret correctly the aberrant sounds. Once again, explanation, encouragement, and example are the answers; it may also be helpful to arrange a practical demonstration.

\section{Failure of Ear Protection}

The universal use of ear protectors in any given noise-hazardous situation is very unusual and is seldom found except where the protectors embody communication devices or the noise level is extremely high. Even if protectors are worn, they vary to a greater or lesser extent in efficiency according to the type used (see the standard deviation values in Table II), and the degree of care in their original fitting and in education in their correct use. These factors of uncertainty, together with the lack of applicability of damage risk criteria to persons who are markedly above average in susceptibility to noise-induced hearing loss, indicate the need for 'monitoring audiometry' in a hearing conservation programme.

By means of such audiometric measurements, 
both management and worker will be safeguarded as the development of noise-induced hearing losses will be detected at an early stage. In addition, the management will be protected against claims for deafness by personnel who may have had hearing impairment at the start of their employment.

\section{REFERENCES}

American Standards Association (1957). Standard Z24-22. Coles, R. R. A., and Rice, C. G. (1965). Ministry of Defence (Navy), R. N. Personnel Research Committee, Report 1049.

- - (1966a). F. Sound Vib., in the press.

(1966b). Letter to the editor. Ibid., 3, 52I.

Dickson, E. D. D., Hinchcliffe, R., and Wheeler, L. H. (1954). Report No. 884, Flying Personnel Research Committee, Ministry of Defence (Air), London.

Fletcher, J. L., and Loeb, M. (I962). F. acoust. Soc. Amer., 34, 1629.
Golden, P. M., and Clare, R. (1965). U.K. Atomic Energy Authority, A.W.R.E. Report E-I/65.

Hershkowitz, J., and Levine, L. M. (1957). F. acoust. Soc. Amer., 29, 889.

Kryter, K. D. (1946). Ibid., 18, 413.

Michael, P. L. (1965). Arch. environm. Hlth., 10, 612.

Munson, W. A., and Wiener, F. M. (1952). F. acoust. Soc. Amer., 24, 498.

Neely, K. N. (1965). Defence Research Medical Laboratory, Toronto, Canada. Personal communication.

Piesse, R. A. (1962). Report No. 21, Commonwealth Acoustic Laboratories, Sydney, Australia.

Pollack, I. (1957). F. acoust. Soc. Amer., 29, 1324.

Rudmose, W. (1962). Congress Report I. Paper H52. Proc. 4th int. Congr. Acoustics, Copenhagen, 1962.

Shaw, E. A. G., and Thiessen, G. J. (1958). F. acoust. Soc. Amer., 30, 24.

Sivian, L. J., and White, S. D. (I933). Ibid., 4, 288.

Thiessen, G. J. (1962). In The Control of Noise. National Physical Laboratory Symposium No. 12, pp. 153. H.M.S.O., London.

Zwislocki, J. (I95I). F. acoust. Soc. Amer., 23, 36.

- (1952). Ibid., $24,762$. 